\title{
Geração hip-hop e a construção do imaginário na periferia do Distrito Federal
}

Breitner Tavares ${ }^{1}$

Resumo: Este artigo propõe observar elementos gerais referentes à construção de um estilo de vida hip-hop em termos de suas origens históricas de uma cultura planetária e, em especial, como fator preponderante para a configuração geracional. Para isso, se discute algumas trajetórias biográficas concernentes a uma configuração da cultura hip-hop vivenciada por jovens do Distrito Federal, compreendida como mecanismo produtor de orientações coletivas para uma determinada visão de mundo.

Palavras chave: Gerações, juventude, hip-hop, rap, Distrito Federal.

\section{Introdução}

\lceil] nicialmente, cabe ressaltar que, dentre as abordagens sobre juventude, a mais difundida se faz através do conceito de gerações desenvolvido por Mannheim (1952), o qual se refere de uma maneira geral a uma noção qualitativa de tempo e como esse tempo está voltado para um processo incessante de mudança social. Assim, a juventude inserida num processo de formação de uma unidade geracional diversa, frente à subjetividade de seus atores, realiza-se na busca de suas metas íntimas, do espírito de seu próprio tempo. Nesse caso, o que importa é analisar as reações e intenções desses grupos, em especial na contemporaneidade.

A juventude exprime reações diferentes frente a problemas semelhantes, observáveis nos diferenciados estilos de vida manifestos. Esses estilos, por sua vez, estão voltados para a busca por participação de espaços políticos em busca de reconhecimento social. A mobilização social a partir de uma posição de classe constitui um fator indicativo de sua posição geracional.

Os movimentos juvenis são relevantes para se entender a configuração de uma geração, pois evidenciam, a partir de sua conduta como sujeitos sociais que participam de vínculos de solidariedade e competição social,
1. Professor adjunto no Instituto de Ciências Sociais da Universidade Federal de Alagoas (Ufal), atuando no Programa de PósGraduação em Sociologia (mestrado); editor revista Latitude; membro do grupo de pesquisa "Educação e Políticas Públicas: Gênero, raça/etnia e juventude" (Geraju). O autor foi bolsista internacional da Fundação Ford (2006-2009) e visiting scholar em estudos étnicos na Universidade da Califórnia, em Berkeley, através da Comissão Fulbright (2007-2008). 
2. Música instrumental combinada com efeitos eletrônicos.

3. O street dance ou dança de rua é um termo amplo que inclui diversos ritmos e performances corporais, que se originou em espaços informais nos Estados Unidos a partir dos anos 1970, com o fluxo de imigrantes de diversas localidades que trouxeram seus ritmos tradicionais e populares, os quais se recombinaram em novas modalidades (Toop, 1984). Em Brasília, o grupo DF Zulu Breakers, formado em Ceilândia-DF desde os anos 1980, se destaca em competições nacionais e internacionais dessa modalidade.

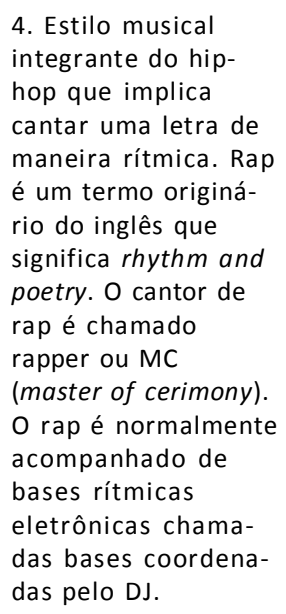
integrante do hiphop que implica cantar uma letra de maneira rítmica. Rap é um termo originário do inglês que significa rhythm and poetry. O cantor de rap é chamado rapper ou MC (master of cerimony). O rap é normalmente acompanhado de bases rítmicas eletrônicas chamadas bases coordenadas pelo DJ.

dentro de uma unidade geracional. Os movimentos sociais, portanto, constituem um importante elemento de auto-organização social dada a importância das características concretas de cada conjuntura histórica de grupos de idade que estão tentando redefinir seu papel social em termos de estilos de vida.

Para identificar, interpretar e avaliar aqueles traços que funcionam como estilos de vida, considera-se que os mesmos foram submetidos a diferentes processos de socialização. Isso ocorre de acordo com diversos condicionantes, como classe, gênero e raça/etnia, entre outros. Eles estabelecerão variados sistemas de distinção e separação social frente a outros grupos. Além disso, os agentes sociais definem sua identidade, enquanto grupo específico com sua dinâmica de transformação ou acomodação, de acordo com a configuração ou o nível de interrelação social com outros grupos. Também aí se encontram afinidades de estilo que são intercambiáveis entre diversas culturas juvenis como aquelas envolvidas como o estilo hip-hop.

Historicamente, o hip-hop se refere ao movimento cultural produzido por jovens negros e latinos, surgido em espaços segregados de grandes metrópoles dos Estados Unidos e da Inglaterra no final dos anos 1960, por intermédio da influência $d u b^{2}$ de origem caribenha que chegava aos EUA trazida por imigrantes. Naquele período, havia uma profusão de estilos subculturais que se estruturavam gradualmente sob a ótica de uma cultura transnacional, globalizada, como ocorria com o rock, o reagge, entre outros.

Como uma dessas práticas culturais difundidas mundialmente, o hip-hop é um fenômeno cultural que engloba estéticas artísticas, como o break ou street dance (dança de rua), ${ }^{3}$ o grafite (pintura aerográfica), o DJ (como produção musical) e o $\operatorname{rap}^{4}$ (como a combinação de ritmo e poesia cantada). De fato, cabe ressaltar que essas diferentes manifestações estéticas foram difundidas de modo heterogêneo, e o rap foi o mais difundido como cultura popular de uma juventude globalizada. O hip-hop, desde sua origem, tem sido associado a uma arte voltada para segmentos excluídos no espaço urbano, como jovens imigrantes, negros, mulheres, entre outros.

Paul Gilroy (2001), intelectual negro britânico, se remete à categoria diáspora como uma proposta para os estudos culturais. Objetiva explicar a formação de uma cultura vernacular do Atlântico Negro. Em sua obra, o autor analisa o estabelecimento de mecanismos de distinção cultural adaptado às novas circunstâncias do Reino Unido, manifestações que atuam em separado e, ao 
mesmo tempo, em convergência. O autor atesta que o povo negro se recria, enquanto grupo conglomerado, ao reinventar sua própria etnia. A retórica do poder negro foi desvinculada de seus marcadores étnicos e, diante de sua condição de explorado, passa à redefinição de seus projetos sociais frente a suas necessidades locais e políticas, a suas histórias de lutas.

O povo negro estabeleceu novas linguagens políticas de cidadania voltadas para a justiça racial e a igualdade. Essas linguagens ultrapassaram a esfera da tradicional luta pelo trabalho e passaram também a se articular através do lazer. A diáspora permitiu a "transferência" de formas culturais e estruturas de sentimentos. Dessa mesma história se originará o hip-hop e suas respectivas manifestações.

Contudo, segundo a discussão que associa a diáspora do Atlântico Negro de Gilroy (2001) com a formação do hip-hop, praticamente não se consideraram aspectos espaço-temporais presentes numa configuração geracional (Weller, 2010: 20). Além disso, o Atlântico Negro do autor se refere basicamente a experiências do Atlântico do hemisfério norte, algo que desconsidera outras especificidades do processo diaspórico colonial sul-americana na formação de uma população afrolatina.

Em outros termos, isso significa que jovens negros afrolatinos, como os do Brasil, em função de outros movimentos migratórios e acesso a bens culturais simbólicos, como o hip-hop e o rap norte-americano, estabelecerão outros elementos constituidores de uma identidade geracional em torno do hip-hop nas grandes metrópoles brasileiras. Portanto, a formação de geração jovem em torno do hip-hop não ocorre simplesmente num processo de assimilação de novos valores numa perspectiva de centro e periferia. $O$ hip-hop produzido de modo diverso sofrerá influência em sua composição, inclusive pela combinação de elementos musicais advindos de outros estilos musicais já existentes e consumidos pelos jovens (Sansone, 2004: 169).

O sentido atribuído à modernidade - como apreciação da racionalidade técnica de valores universais eurocêntricos - influenciou através de um sistema mundial toda cultura existente através da colonialidade (Quijano, 2000). Dito de outra forma, esse projeto monolítico de modernidade ocidental imprimiu valores que se relacionam às outras culturas e demais povos a partir de uma posição de superioridade incapaz de perceber através de cosmologias e epistemologias de um mundo não ocidental (Grosfoguel, 2007). 
Diante disso, o hip-hop produzido por uma juventude em grandes centros urbanos, como em regiões da América Latina, apresenta respostas a partir da subalternidade imposta pela colonialidade de um sistema mundial de valores e produtos simbólicos centrado numa modernidade ocidental. Essa resposta se materializa através da recriação de estilos e novas formas de pensamentos e estratégias de ação nas esferas simbólicas, políticas e econômicas de um sistema em escala mundial.

Assim, esse conjunto de práticas constituídas pela juventude contemporânea remete a uma forma de pensamento fronteiriço, que é, em parte, influenciado pelas condições de opressão estruturadas historicamente. Contudo, essa mesma situação permite uma reflexão e a criação de novas estratégias e lutas pela liberação (Dussel, 2008) e redefinição do próprio sentido de humanidade estruturado hierarquicamente a partir de categorias como gênero, raça/etnia, classe, entre outras.

2. Mecanismos simbólicos de inserção:

A luta por reconhecimento

Enfrentar a discussão relativa às origens do hip-hop significa ir além da "realidade mítica" de uma música que nasceu nos guetos negros dos Estados Unidos, pois esse estilo musical já se encontra difundido tanto no Brasil como em outras localidades na forma de um produto da indústria cultural globalizada.

O hip-hop expresso pelos jovens rappers costuma veicular, através da música, a construção de uma consciência política. Eles falam em nome de uma geração sem voz, periférica, estigmatizada. Nesse caso, a prática cultural do rap propicia a emergência de uma consciência social dos indivíduos em termos de diversas perspectivas, relacionadas a gênero, raça/etnia. Essa postura combativa define um sentimento de pertencimento coletivo em termos de uma espacialidade injusta materializada na periferia urbana. Isso significa que, mesmo estando em diferentes países ou cidades, a juventude hip-hop poderá redefinir suas questões geracionais estabelecendo semelhanças e contrastes em relação ao seu envolvimento com os grupos de rap, bem como ao enfrentamento de situações discriminatórias, como é observado entre jovens rappers de São Paulo e Berlim (Weller, 2010).

No caso brasileiro - em relação a outros gêneros de música popular de identidade negra, como o samba, o pagode, o axé, entre outros -, o rap assume 
um discurso ao mesmo tempo de orgulho do povo negro e de crítica ao racismo, denunciando, em tom autobiográfico, sua revolta contra a ordem estabelecida e contra um "destino" de contínua exclusão (Carvalho, 1994: 32).

Esses grupos, portanto, aparecem como alternativa aos grupos juvenis, constituem uma nova forma de rebelião, na qual se reúnem em "galeras" que não possuem a organização própria das gangues. Ao contrário: podem servir como opção efetiva para o jovem situar-se no espaço público no debate sobre a sociedade e conferem um caráter de visibilidade às aspirações dos diferentes grupos que englobam.

O hip-hop, de fato, reúne em suas manifestações alguns aspectos que o aproximam daquilo que passou a se definir como "novos movimentos sociais". Esses movimentos "mais soltos", a que se refere Gohn (2004), são flexíveis, abertos em termos de valores e ideologias. Gohn observa que os movimentos sociais na atualidade se articulam mediante redes estabelecidas por pequenos grupos, que, numa relação de compreensão mútua, constroem suas demandas na vida cotidiana, em que a afetividade e a identificação pessoal passam a ser a base para práticas inovadoras da cultura. Contudo, o hip-hop não pode ser definido como movimento social unívoco, pois, na medida em que se organiza no sentido de suas demandas e reivindicações para ações específicas, seus membros passam a articular e veicular suas falas a partir de redes externas, como instituições vinculadas ao local geográfico: os "movimentos da periferia", ONGs - Central Única das Favelas (Cufa), Movimento Hip-hop Organizado ( $\mathrm{MH} 2 \mathrm{O}$ ), Grupo Atitude, entre outras) -, pequenas e médias empresas, como gravadoras de vários segmentos da indústria fonográfica, igreja, escola, entre outros setores.

\section{Gênero e raça e hip-hop}

O hip-hop representa, a partir de sua estética, propostas políticas, um tipo de arte social, com apelos frente à questão da exclusão social (classes), da marginalização no espaço urbano expressa através da construção de um imaginário da periferia (Forman, 2002), frente à questão da segregação racial e, mais recentemente, à questão de gênero (Pough, 2004). No hip-hop, e em especial no rap, há um discurso voltado ao jovem das classes sociais populares e, em especial, ao negro, configurando um meio de expressão afirmativa. Contudo, mesmo os estudos pós-coloniais, como os enunciados por Gilroy (2001), atestam a conotação misógina e masculinista que expressa uma relação de conflito entre homens e mu- 
Iheres (negros e negras) no contexto norte-americano, como discutidos por Ferguson (2007) e Rosa (2006).

O discurso originário da emancipação racial negra tem entrado em certas ocasiões em dissonância devido à construção conflitante da sexualidade. Parece cada vez mais inviável uma separação destas questões raciais e de gênero, presentes nas articulações estratégicas advindas do repertório de procedimentos enunciativos do rap.

Os estudos multiculturais lidaram historicamente com a desconstrução da categoria "classe" de aspecto generalizante, ao afirmar que essa só poderia ser vivenciada por indivíduos dotados de "raça". A questão do conflito instaurado por um masculinismo no hip-hop chama a atenção para outro aspecto a ser problematizado: "o gênero é a modalidade na qual a raça é vivida" (Gilroy, 2001: 180). Em outros termos: o corpo é fator significante que dá lugar a conteúdos variados, portanto, ao considerar questões de gênero desvinculadas dos aspectos de racialidade corre-se o risco de outro tipo de universalismo.

A diferença estabelecida pela raça constrói novas variantes simbólicas nas relações masculino-feminino, as quais são naturalizadas no interior da vida familiar patriarcal e, da mesma forma, reproduzem referências de identidades raciais consideradas estáveis (Gilroy, 2001: 180).

O hip-hop permite a circulação em termos planetários do discurso de uma identidade racial como manifestação proveniente da diáspora africana, que é agora reinterpretada sob configurações de gênero e sexualidade. Enquanto bem simbólico produzido no contexto da produção estética da juventude negra na contemporaneidade, trouxe aspectos de reconstrução e positivação dos negros e dos excluídos. A questão de gênero - mais especificamente da misoginia presente em relações desiguais da juventude - estabelece novas frentes por uma mobilização que contempla demandas de atores sociais contrários ao racismo e ao sexismo.

4. Etnografia urbana:

Juventude hip-hop no Distrito Federal

O hip-hop se posiciona de modo divergente à perspectiva dos estudos culturais que enfatizaram os estudos de subculturas nas gerações jovens com posicionamento de vanguarda frente ao mercado de consumo da indústria 
cultural. Em relação a isso, no Brasil , especificamente em Brasília, sempre esteve inserido num mercado de bens simbólicos e materiais, como discos, roupas e acessórios veiculados pelos meios de comunicação de massa, a partir de programações em rádios especializadas ou programas de entretenimento na TV com videoclipes em cadeia nacional. Em geral, são músicas e vídeos de grupos norte-americanos que delineiam toda a construção de um gosto pelo consumo de bens culturais da juventude que passa a se identificar o hip-hop em grandes metrópoles brasileiras.

DJ Antigas: normalmente, os lançamentos do Michael Jackson paravam tudo. $\mathrm{O}$ clipe do Michel Jackson, naquele tempo até que com o tempo começou a passar o break. Na TV existia um programa, era de um camarada chamado Jota Silvestre, lá de São Paulo, aí tinha um concurso de break, em 1982, a gente ficava louco, assistindo aquilo ali, e as paradas e os caras fazendo as ondas assim... e as músicas e a gente enlouquecia porque não tinha acesso, a gente assistia direto. ${ }^{5}$

O hip-hop surge em Brasília concomitantemente a outras metrópoles brasileiras, como Rio de Janeiro e São Paulo. Contudo, Brasília, devido às suas especificidades de capital federal, bem como pela presença massiva das embaixadas, propiciou um intercâmbio entre jovens de uma classe média alta com acesso a viagens internacionais, ao consumo de discos, videoclipes e tecnologias de produção musical que inexistiam no país até aquele momento. O consumo de discos de funk e rap por jovens da classe média brasiliense trouxe os primeiros materiais para suprir as rádios. Filhos de artistas ou servidores públicos, esses jovens estavam mais próximos das inovações tecnológicas e estéticas já no início dos anos 1980.

Pode-se afirmar que Brasília, devido ao seu projeto de abrigar uma classe burocrática dirigente, estava mais voltada paras as questões nacionais (Nunes, 2004). Sua dinâmica urbana era restrita ao Plano Piloto. A sociabilidade urbana com as demais cidades do Distrito federal se dava mais em função da oferta de mão-de-obra para prestação de serviços domésticos e para a construção civil. As cidades do Distrito Federal tornavam-se invisíveis no que se refere à sua produção local de cultura e outros bens simbólicos.

Pensar o surgimento do hip-hop no Distrito Federal significa, dentre outras coisas, lançar-se no movimento pendular das migrações diárias que inscrevem, física e metaforicamente, o sentido de centro e periferia na do espaço urbano vivenciado pela juventude. Contudo, o caminho de desenvolvimento
5. Nesta seção, parte da visão de mundo da juventude hip-hop será recuperada a partir de fragmentos retirados de duas entrevistas com dois DJs dos anos 1980, apresentados com nomes fictícios. DJ Antigas tem 40 anos e é morador de Ceilândia, atuou em diversos grupos de rap nos anos 1990, é casado e vive do seu trabalho como DJ. O DJ Virada tem 39 anos, é morador do Plano Piloto e pertence à classe média que introduziu o hip-hop como bem de consumo na cidade, na forma de discos e gravações. Ele é casado e trabalha como produtor musical. 
seguido pelas cidades, no caso do Distrito Federal, cria espaços cada vez mais heterogêneos, portanto, sempre mais complexos da produção do consumo de lazer das juventudes.

\section{Os arquivos jornalísticos e a imagem da juventude no Distrito federal}

A partir de um levantamento feito junto ao Correio Braziliense - jornal de maior circulação no Distrito Federal - foram pesquisados arquivos das edições diárias de 1985 a 1994. A seleção esteve voltada para artigos que tratassem de temas relacionados à juventude e ao lazer nas cidades-satélites.

De fato, as dezenas de horas de trabalho permitiram a constatação de que, até os anos 1980, as atividades de lazer, bem como a produção cultural do Distrito Federal se restringiam ao Plano Piloto. O jornal possuía um caderno chamado "Brasília", no qual eram reportados fatos da cidade, incluindo-se as atividades de lazer. Havia também o caderno "Dois", relacionado a uma escassa programação cultural também concentrada no Plano Piloto. O caderno "Cidades" só seria criado no início dos anos 1990. Nesse período, os acontecimentos relacionados às demais cidades-satélites e à sua juventude se restringiam aos cadernos policiais e esportivos.

Os artigos tratavam basicamente de fatos envolvendo tráfico de drogas, acertos de contas, homicídios, que, em sua maioria eram cometidos ou sofridos por jovens. Além disso, havia a associação de diversos grupos de jovens ligados a manifestações culturais nas cidades-satélites com a violência e a formação de gangues.

A juventude envolvida no hip-hop, especialmente em grupos de break, era criminalizada a partir da perspectiva das gangues e tribos urbanas. As matérias utilizavam-se de um jargão técnico para descrever as terminologias dos grupos, bem como aspectos relacionados aos estereótipos da indumentária, como cabelos e roupas. Contudo, as trajetórias sociais e orientações coletivas dos jovens eram suprimidas, em seu lugar, generalizações de cunho policialesco associavam todos os jovens à delinquência e referenciais de um imaginário de "gangues nova-iorquinas".

Paralelamente à invisibilidade e criminalização da juventude negra das periferias de Brasília pela mídia jornalística, surgiram, nos anos 1980, alguns programas de rádio que se tornaram um veículo representativo das atividades relacionadas ao lazer da juventude das cidades-satélites. Essas rádios 
promoviam programas especializados em ritmos como o funk e rap, relacionados ao estilo hip-hop, e eventos como festas, "sons", ${ }^{6}$ em diversas localidades. Além disso, essas rádios promoviam concursos de gravações de mixagens que eram produzidas por pequenas equipes de sonorização espalhadas pelas cidades e responsáveis por pequenas festas locais.

DJ Antigas: Mais do início do esquema, aqui em Brasília, eram as rádios FM, a Antena 01, hoje da 93.7, a Atlântida FM, que tinha um programa que chamava dance night. Era sexta-feira, de $23 \mathrm{~h} 00$ à 00h00, e dia de sábado, de 00h00 a 1h00 da manhã. [...] Então o que chegava pra gente era o que os caras falavam, era o que a gente entendia.

Dentre esses vários programas, o "Mix Mania”, do DJ locutor Celsão, era um dos mais ouvidos. Celsão, além de locutor de rádio, era DJ em boates, ou, durante o dia, animava festas conhecidas como "ruas de lazer", quando diversos grupos organizados apresentavam performance de break em concursos com premiações. A organização dos jovens em grupos que disputavam através da dança o reconhecimento de seus interlocutores era associada genericamente a gangues.

Os primeiros espaços representativos para as festas com música funk e rap ocorriam em bairros nobres, como o Lago Sul, num espaço conhecido como "Gilbertinho" e na "Fonte do Bom Paladar", onde ocorreram os primeiros encontros em torno do break e rap, que eram reproduzidos nas rádios. Jovens de diversas cidades - Ceilândia, Gama, Guará - se encontravam e estabeleciam contatos e criavam grupos por afinidade em relação ao estilo hip-hop.

Até o final dos anos 1980, o rap enquanto gênero musical internacional não tinha a carga crítica que iria adquirir a partir dos anos 1990, como visto em grupos americanos, como o Fat Boys. As letras em geral tratavam de temas lúdicos, desprovidos de carga crítica, conhecidas no Brasil como "melô".7 Essa perspectiva mais lúdica sem um discurso politizado influenciava o Brasil, que chegava a se utilizar do gênero como recurso publicitário ou humorístico. Já havia algumas propagandas que se utilizavam do rap como meio comercial em São Paulo e no Rio, mas o primeiro grupo de rap a produzir um disco no Brasil foi o grupo DJ Raffa e os Magrelos, formado por jovens do Plano Piloto e do Guará. Em seguida, surgiram outros grupos em São Paulo, como o do Thaide e DJ Hum e Pepeu.
6. "Sons" era o termo atribuído a festas informais, familiares, que ocorriam em casa de particulares nas cidades-satélites nos anos 1980. Em geral, eram festas locais ao ritmo de funk, rap e outros gêneros musicais. Os "sons", devido ao seu caráter local, eram frequentados pela vizinhança e normalmente não havia a necessidade de um convite formal para participar.

7. Os melôs eram músicas que tomavam uma base de um ritmo funk norte-americano e sobrepunham à melodia e ao ritmo uma letra em português que tratava de temas simples do cotidiano. Em geral apresentavam um sentido cômico. Um dos pioneiros desse gênero foi o "melô do tagarela", de Miéle. Os melôs também são associados a um hip-hop acrítico, que será posto em cheque pelo "rap consciência"

(Carvalho, 1994), mais conhecido, posteriormente, como "rap nacional". 
DJ Antigas: Foi daí que começou o esquema e a galera ficou conhecendo o primeiro movimento forte, forte assim onde todo mundo de Brasília se encontrou. Foi ali que todo mundo começou ver a cara um do outro, uma foi no Gilbertinho numa boate que chama Legróbio. $\mathrm{O}$ primeiro encontro hip-hop passou até na rádio! "Caraca véio", tenho que ir lá, lá era uma boatezinha pequeninha estava Rap, estava Wave, estava galera que antigamente era da banda do ( ) que era ( ) o Kid, os Ventanias, a galera toda, o Jony que... eu nunca tinha visto alguém fazer scratch, estava lá o Leandro arranhando o aparelho de scratch, tá ligado, foi o primeiro cara que eu vi fazendo scratch.

Nesse contexto, a criação dos primeiros espaços para encontro de jovens envolvidos no hip-hop através do break e do rap ocorreu no Plano Piloto, bem como o pioneirismo dos grupos do DJ Raffa e os Magrelos demarcam um momento relevante para pensar o hip-hop brasiliense como um fenômeno de classe média. Por outro lado, seu público era majoritariamente da periferia das cidades-satélites que iam em busca de entretenimento e das inovações musicais que a cidade passa a ofertar.

Nesse período, muitos jovens formaram grupos de break e rap e muitos jovens das cidades-satélites passaram a interagir com os jovens de Brasília interessados em break e rap. Em meio à "capital do rock", como Brasília era conhecida, por seu grande número de bandas, os poucos jovens do Plano Piloto que se interessavam por hip-hop decidiram frequentar festas, "sons" nas cidades-satélites. Em geral, esses jovens se identificavam mais com os jovens das periferias. Portanto, isso interferiria em sua sociabilidade local no conjunto das superquadras de Brasília, onde seus melhores amigos passaram a ser os "fiIhos dos porteiros", que também tinham o mesmo tipo de afinidade musical.

DJ Virado: De repente eu comecei a me sentir muito mais em casa nesses lugares, era muito mais bem recebido, não tinha frescura, eu me identificava com as pessoas. Estranhamente a minha vida toda começou a ir pra lá, praticamente eu só morava aqui, mas eu não tinha praticamente amigos. Pra você ter uma ideia, você pode até achar engraçado, mas os meus melhores amigos aqui na quadra eram filhos de porteiro e a minha mãe confirma isso. Então, não sei o que que acontecia, a minha afinidade social era diferente.

A interação entre os jovens de famílias mais abastadas do Plano Piloto e dos jovens pobres das cidades-satélites gerou uma polarização de um campo 
de produção do hip-hop que uniu DJ, b-boys, rappers e grafiteiros, no sentido de estabelecer contatos com um circuito mais estruturado. Isso ocorreu primeiramente nas boates em Brasília, como a Kremelin (Cruzeiro), o Galpão Dezessete (Sobradinho), Paradão e City (Taguatinga), o Primão e o Quarentão (Ceilândia). Posteriormente, após um circuito estruturado de boates e meios de divulgação, como as rádios, as produções do rap brasiliense passam a polarizar, em nível nacional, a partir de grupos como gravadoras fonográficas localizadas em São Paulo, através da Equipe Cascatas.

Essa associação entre diversos jovens permitiu a inserção de alguns grupos que iriam posteriormente estabelecer outro centro geográfico da produção de música popular como o rap para além do Plano Piloto. Portanto, gradualmente, os espaços representativos do hip-hop no Distrito Federal voltam-se mais para as cidades-satélites, como foi o caso de Ceilândia, representada por grupos de break como Reforços, DF Zulu Breakers, grafiteiros e rappers, como os do grupo Câmbio Negro.

Essa nova dimensão do movimento hip-hop no Distrito Federal, agora articulada nas cidades-satélites, em especial em Ceilândia, cria uma situação inusitada no campo da produção cultural do Distrito Federal, já no final dos anos 1980 e no início da década de 1990. Ceilândia se torna uma cidade representativa em termos de um circuito de produção do rap nacional que lançará grupos como GOG, Câmbio Negro, Álibi, Cirurgia Moral, Viela 17, Tropa de Elite, entre outros. Diversos grupos que iriam definir um campo de produção do rap nacional, como os Racionais MC ou Thaide, passaram por Ceilândia.

Essa diversidade de grupos desenvolveu uma cadeia de produção realizada por jovens da própria cidade que contatavam os grupos de outros estados que vinham se apresentar no Distrito Federal, às vezes sem passar pelos espaços da cultura oficial de Brasília. Essa relativa autonomia de Ceilândia, constituída no campo da produção do rap, representa um esforço coletivo de diversos grupos do Distrito Federal no sentido de mobilização de jovens da periferia que se identificavam com o estilo hip-hop.

Inicialmente, o Distrito Federal não contava com gravadoras e produtores profissionais, o que levava os grupos inicialmente a se dirigir a São Paulo para uma carreira profissional. Posteriormente, surgem algumas gravadoras em Brasília, como a Discovery. Contudo, em geral, os jovens envolvidos no rap tinham criatividade, mas pouca experiência como empreendedores. 
Não há dados precisos disponíveis sobre a tiragem de discos, apesar de se contarem mais de vinte grupos com gravação de discos nos anos 1990 . Poucos contudo lograram o sucesso financeiro correspondente.

DJ Antigas: Ele [o proprietário] vendeu a gravadora para um cara, ele abriu mão de tudo em vez de dispensar os artistas, não, ele deixou tudo na mão do cara e está na mão do cara até hoje os direitos, está tudo lá na mão do bicho. Aí o cara continua fazendo e ganhando, a gente não tem direito a nada, ele fez a gente assinar documento pra sair da gravadora, a gente tinha que assinar documento, a gente assinou, veio, aí estava lá constando que a gente não recebia nada, que a gente não recebe mais dele.

\section{Trajetórias Juvenis/Marcos Geracionais: \\ Fúria Funk na Periferia de Ceilândia - DF}

8. Estilo musical definido pela combinação de vários elementos rítmicos e melódicos, a partir de um instrumental tecnológico que passou a ser disponibilizado, a partir dos anos 1970 principalmente pela juventude negra norte-americana.
Nos anos 1980, as cidades do Distrito Federal possuíam poucos recursos destinados às atividades de lazer para a juventude. A cidade de Ceilândia destacava-se como referencial para a compreensão da juventude que frequentava as chamadas rua de lazer. Esse tipo de festa pode ser considerado como prática estética organizadora de formas de sociabilidade e experiência constitutiva de uma base subjetiva nas sociedades urbanas contemporâneas. Em cidades como Nova lorque e São Paulo, jovens de diversos bairros se encontravam para dançar break e funk, ${ }^{8}$ normalmente no centro metropolitano, próximo a estações rodoviárias ou de metrô (Ferguson, 2007; Vianna, 1988).

No Distrito Federal, os jovens se encontravam em boates ou próximos a espaços comerciais, como o Conic e o Conjunto Nacional (Amorin, 1997). Em cidades como Ceilândia, ocorriam festas em áreas às vezes sem qualquer pavimentação, próximas ao comércio local, onde se reuniam muitas galeras de várias localidades. Os mais virtuosos se revezavam dançando o break e o funk. Havia as chamadas "equipes de som", compostas por DJs e alguns auxiliares, que eram verdadeiros técnicos em sonorização. Havia desde a pequena Vôo Livre até a famosa Smurfs Disco Dance, considerada a maior equipe de som de Brasília, nos anos 1980, cuja administração era realizada por Marquinhos.

No cenário funk, existiam regras que definiam o lugar de cada um no contexto da festa. Os funkeiros, como eram denominados genericamente, buscavam elaborar uma resposta diferenciada daquelas disponíveis no merca- 
do. Esses jovens se apropriaram de forma peculiar dos objetivos providos pelo mercado, pela indústria cultural, imprimindo novos significados pela inversão de uso ou pela reunião de diferentes objetos num conjunto inusitado, criando, assim, um estilo subcultural peculiar. O lazer pode ser considerado um tipo de festividade carnavalesca:

Forma primeira, marcante, de civilização humana [...] onde há uma abolição provisória de todas as relações hierárquicas, privilégios, regras ou tabus (Bakhtin, 1999: 17).

A categoria hibridismo tem sido utilizada para definir as culturas diaspóricas dentro da lógica da tradução, como considera Bhabha (2003).

O Quarentão foi um dos espaços mais representativos da cultura hip-hop existente nos anos 1980 em Ceilândia. Tratava-se de um prédio que pertence à Administração Regional. Localizado na parte central da cidade, ao lado do comércio regular e cercado pelo comércio informal dos camelôs, era uma espécie de salão de múltiplas funções, utilizado para vários fins sociais. Aos domingos, à noite, aconteciam os "sons" animados pelo DJ Gersom. Por sua posição central, tornou-se um polo irradiador dos funkeiros de Ceilândia, bem como de outras localidades vizinhas. Só era permitida a entrada de jovens acima de 18 anos. O local era famoso por ser uma das únicas opções da juventude, geralmente oriunda de classes sociais populares, e por ser espaço de confronto entre jovens de diferentes localidades.

DJ Antigas: Quarentão era um esquema, é lógico que rolava o rap, mas o esquema do Quarentão era da galera, dos bandidão velho, ${ }^{9} 0$ Quarentão era dos bandidão doido, era por isso que o Quarentão era muito louco, era por isso que os bandidos tudinho iam, curtiam no Quarentão velho, lá dentro quase não tinham desavenças, as paradas eram lá fora mesmo, muita gente que morreu e tal, mas lá dentro era tenso, mas era prazeroso estar ali no meio.

O Quarentão foi um dos responsáveis pelo surgimento de um cenário artístico hip-hop em Ceilândia. Logo à frente Quarentão, existia uma espécie de anfiteatro onde jovens se reuniam para treinar coreografias de break, o que era promovido pela entidade social DF Zulu Breakers.

Nos anos 1990, inicia-se a estruturação de vários grupos de rap que deixaram de lado as letras cômicas, como as dos melôs, e passaram a aderir a
9. "Velho" é um termo utilizado para se referir a uma pessoa qualquer, algo como "cara", "sujeito" ou "meu caro". 
10. No ano de 1993, ocorre em Brasília a morte do jovem Marco Antônio Velasco por uma gangue de lutadores de artes marciais do Plano Piloto, chamada Falange Satânica. $O$ caso revela a existência de gangues de jovens de classe média envolvidos em atos de violência e crimes. Diante disso, a imprensa local cria um estereótipo e todos os grupos de jovens existentes no Distrito Federal passam a ser tratados como disseminadores de violência. narrativas que abordavam problemas sociais, usando um tom ao mesmo tempo de denúncia e reivindicação de mudanças sociais, com letras que abordam questões como o racismo e a violência nas periferias.

Nesse período, o Câmbio Negro liderado por jovens de Ceilândia, foi um dos grupos a alcançar maior repercussão frente à juventude. Antes do sucesso comercial e de seu reconhecimento pela juventude do Distrito Federal, o Câmbio Negro é citado na mídia como uma dentre várias gangues de delinquentes, que estariam "espalhando o terror" no Distrito Federal. ${ }^{10}$

Câmbio Negro marca o período de estruturação do rap produzido no Distrito Federal e no país, junto com outros grupos, como Racionais MC, de São Paulo, e MV Bill, do Rio de Janeiro. Criado por jovens negros, produziu um rap que atingiu diversas camadas sociais, até mesmo as classes médias, especialmente a partir da música Sub-raça, a entrada de uma linha discursiva sobre a exclusão racial em Brasília. Trata-se da construção do imaginário da periferia da capital do país, que reproduz todo um quadro de exclusão social, objeto do discurso crítico frente à segregação social típica das grandes metrópoles. O trecho da música Sub-raça discute a exclusão sob a ótica da segregação racial e sugere uma "consciência negra".

Agora irmão vou falar a verdade,

A crueldade que fazem com a gente,

Só por nossa cor ser diferente.

Somos constantemente assediados pelo racismo cruel,

Bem pior que fél, é o amargo de engolir um "sapo", só por ser preto, isso é fato.

O valor da própria cor não se aprende em faculdades ou colégios que ser negro nunca foi um defeito será sempre um privilégio.

Privilégio de pertencer a uma raça,

Que com o próprio sangue construiu o Brasil...

Sub-raça é a puta que pariu!!!

No verso "não se aprende em faculdades ou colégios que ser negro nunca foi um defeito" apresenta-se a falta de referencial de identificação racial por parte de instituições como a escola, resultante de um racismo que não vislumbra a categoria raça como resultado de uma construção política e social. "É a categoria discursiva em torno da qual se organiza um sistema de poder socioeconômico, de exploração e exclusão - ou seja, o racismo" (Hall, 2003: 69). A letra contrapõe-se ao discurso de inferioridade racial negra. Sub-raça 
reage à condição subalterna da diferença em um jogo que supera o tradicional binarismo dominador/dominado. Apesar de a afirmação em relação a uma negritude ser frequente, isso não significa que essa juventude se reconheça ou mesmo se afirme "negra". A categoria negro, na verdade, não é homogênea, mas resultado de construções que podem apresentar certas ambiguidades, como discutem Carvalho (1996), Fanon (2008) e Sansone (2004).

Em 1994, Câmbio Negro chega ao público do Plano Piloto com apresentações nos espaços mais representativos da cidade. Isso permite uma redefinição da imagem social do grupo junto aos meios de comunicação. O grupo, que outrora era citado nas páginas policiais do caderno "Cidades", torna-se matéria de capa do caderno de cultura, o "Dois". ${ }^{11}$

Numa dessas edições, há uma matéria intitulada "Sem papas na língua", com o vocalista do Câmbio Negro X (Equis), junto a outros rappers do Distrito Federal, como GOG e Dino Black, na expressam suas expectativas de futuro sobre a política nacional com a eleição do novo presidente, em ano de campanha eleitoral. Em outras matérias, os jovens lançam comentários antirracistas, contra a segregação socioespacial de Brasília. Alguns assumem mesmo suas posições político-partidárias.

Geralmente, o rap procura manter uma posição de arte social a serviço de uma conscientização da juventude excluída; observa-se quase que permanentemente o apelo à "periferia negra de Brasília". O estigma do lugar perpassa todo o imaginário hip-hop como o lugar onde se materializam todos os males da modernidade, desde a violência urbana às drogas, assim como a falta de perspectiva e o racismo.

Até o final dos anos 1980, a representação das cidades do Distrito Federal partia exclusivamente de um princípio de negatividade das cidades-satélites, tendo Ceilândia como um referencial de um imaginário urbano e estigmatizado que criminalizava a juventude através de estereótipos da formação de gangues de delinquentes. Diante disso, o hip-hop especificamente através do rap, permitiu a formação de grupos de jovens em torno do estilo de vida hip-hop, que assume uma luta concorrencial pelos espaços de difusão da cultura local. Gradualmente, esses grupos adquirem relevância no campo artístico regional e nacional, o que Ihes conferiu um status diferenciado de artistas produtores de cultura. Essa inserção da juventude de Ceilândia, no início dos anos 1990, permitiu que através de um movimento cultural se polarizassem questões na esfera política.
11. "Sem papas na língua: Ligados em tudo, os rappers GOG, X e Dino Black dão o seu recado aos candidatos às próximas eleições". Reprodução da matéria do jornal Correio Braziliense, caderno "Dois", 10 de setembro de 1994. 
Esse processo de inserção política de uma juventude em busca de reconhecimento social para suas questões através do rap possibilitará a inclusão de questões relacionadas à juventude da classe trabalhadora, bem como um processo de institucionalização do rap em função o lançamento de alguns candidatos ao parlamento local oriundos do hip-hop ou que se utilizam dessa indumentária para a construção de sua plataforma política, como ocorreu com X, pelo PPS, em 2002, e Flávio Rap, pelo PP, em 2006, e, finalmente, do DJ Jamaika, ligado a coligações evangélicas, em 2010, os quais concorreram e concorrem a uma vaga na Câmara Legislativa do DF.

\section{Novas configurações geracionais no rap no Distrito Federal}

No final da década de 1990, com a popularização de novas tecnologias informacionais, que substituíram os antigos discos de vinil pelo $C D$, associada à prática da pirataria, geraram-se impactos decisivos na produção e difusão de novos grupos. Programas de informática permitiram a criação de estúdios de gravação mais simples e econômicos. Diversos grupos passaram a produzir seus próprios trabalhos, construindo redes de distribuição. Comunidades virtuais tornaram-se fóruns de divulgação e discussão do rap como música independente.

Em feiras livres, como na Feira do Rolo, em Ceilândia, é possível encontrar produtores locais vendendo CDs com bases rítmicas prontas, criadas com baterias eletrônicas e samplers digitais, possibilitando, com aparelhos de som domésticos e algumas letras, a criação de estúdios de ensaio para novos grupos de rap. Com a relativa popularização de câmeras digitais, os novos jovens cineastas do hip-hop já produzem seus próprios videoclipes.

12. Link para o clipe "Carro de malandro" na internet: http:// www.youtube.com/ watch?v=X7FE1RQueg. A distribuição fica a cargo de espaços de divulgação, como o You Tube. Clipes são divulgados em profusão, como "Carro de malandro", ${ }^{12}$ do grupo Tribo da Periferia, com quase dois milhões de acessos, grupo desconhecido dos grandes circuitos comerciais do rap nacional, mas um referencial para juventude pobre que frequenta as lan houses.

A facilitação dos meios tecnológicos de produção e a pirataria não eliminaram a grande indústria fonográfica, mas, sem dúvida, a tornaram mais heterogênea e complexa. No Distrito Federal, ainda há a influência de produtores, chamados por alguns de "padrinhos", que dispõem de prestígio social junto aos meios de divulgação tradicionais. Entretanto, atualmente há muitos grupos que produzem rap em suas comunidades, utilizam a escola, ONGs e outros espaços públicos para divulgar os seus trabalhos. Esses jovens pro- 
duzem seu rap e criam grupos, as "famílias". Os jovens, dessa forma, estão relativamente envolvidos nas questões locais das cidades em que vivem, participam de movimentos sociais ou de trabalhos sociais em ONGs. O habitus constituído em torno do seu estilo de vida irá configurar suas estratégias de denúncia e propostas para o enfrentamento de problemas sociais como a violência urbana e o racismo.

DJ Antigas: Tipo assim, antigamente, pra você gravar um disco no DF, só tinha dois caras que produziam: o Raffa e o Leandrônico. 0 Leandrônico largou de mão o esquema, casou e tal, aí sobrou pro Raffa. Aí o Raffa montou na égua, lavou a égua, todo mundo que queria produzir tinha que ser com o Raffa. Aí ele cobrava o que ele queria cobrar, ele ganhou dinheiro demais da galera. Aí cerca de dez anos pra cá, a parada mudou, porque a galera foi tendo acesso a computador, acesso a software. Aí quer dizer, acabou, se ele cobrava mil reais por música, hoje ele cobra trezentos, entendeu?

Em relação ao gosto musical dos jovens, apesar dos mesmos reiterarem sua predileção pelo rap, em conversas informais admitem frequentar outros ambientes, especialmente rodas de pagode e, eventualmente, forró, quando querem se divertir e encontrar outras pessoas. No que se refere à influência de ritmos diferenciados - como o samba ou o maracatu -, apesar de serem considerados referenciais de uma negritude, são menos difundidos entre os jovens pobres da periferia. De fato, há grupos de rap, como o GOG, que realizam parcerias com músicos associados ao conceito mais geral de música popular brasileira (MPB), como Maria Rita ou Lenine, contudo, esse tipo de parceria leva o rap para o público consumidor universitário de classe média, mas não populariza necessariamente esses estilos em meio à juventude de classe popular.

O hip-hop, enquanto escolha existencial, permite a construção de uma linha narrativa sobre suas expectativas de futuro, o amor e a sexualidade. Esse estilo de vida expresso a partir de uma subcultura apresenta uma configuração específica de relacionamento entre os jovens em que o sexismo, às vezes, é desafiado. Nos últimos anos, há o reconhecimento da atuação feminina no hip-hop, com a entrada em cena de personagens como Vera Verônica, Atitude Feminina, BsB Girls, entre outros, que tematizam a questão da mulher no hip-hop, denunciando a misoginia que atravessa a relação entre jovens nesse estilo de vida. 
Abstract: This article observes some general elements about the construction of hip hop's life style in terms of its historical origins of a planetary culture and in special, as around the young culture as preponderant factor for the generation configuration. Consequently, this paper analises some biographical trajectories about the configuration of the hip-hop culture lived deeply by young people in Brasilia (Federal Distric) - Brazil, understood as a mechanism of its collective social role and vision of world. Words key: Generations, youth, hip-hop, rap, Brasília.

\section{Referências}

Carvalho, José (1994). "The multiplicity of black identities in brazilian popular music", "Série Antropológica", Departamento de Antropologia, Universidade de Brasília.

Dussel, Enrique (2008). Twenty Theses on Politics. Latin America in Translation.

Fanon, Frantz (2008). Pele negra, máscaras brancas, Salvador: EdUFBA.

Ferguson, Ann (2007). Bad boys. Public schools in the making of Black masculinity, Nova York: University of Michigan Press.

Forman, Murray (2002). The hood comes first: Race, space, and place in rap and hip-hop, Middletown: Wesleyan University Press.

Gilroy, Paul (2001). O Atlântico Negro. Modernidade e dupla consciência, Rio de Janeiro/São Paulo: Ucam/Editora 34.

GoHn, Maria da Glória (2004). Teorias dos movimentos sociais. Paradigmas clássicos e contemporâneos, São Paulo: Loyola.

Grosfoguel, Ramón (2005). "The implications of subaltern epistemologies for global capitalism: Transmodernity, border thinking and global coloniality", in William I. Robinson \& Richard Applebaum (eds), Critical globalization studies, Londres: Routledge.

- (2007). "Decolonizing political-economy and post-colonial studies: Transmodernity, border thinking, and global coloniality", in Jose Saldivar \& N. Maldonado-Torres (orgs), Unsettling post-coloniality: Coloniality, transmodernity and border thinking, N. Carolina: Duke University Press. 
HaLL, Stuart (2003). Da diáspora: Identidades e mediações culturais, Belo Horizonte: Editora UFMG.

Mannheim, Karl (1952). "The problem of Generations", in idem, Essay of sociology of knowledge [introdução e organização: Paul Kecskemeti], Londres: Routledge \& Kegan Paul.

NunEs, Brasilmar (2004). Brasília: Fantasia corporificada, Brasília: Paralelo 15.

PougH, Gwendolyn (2004). Check it while I wreck it, Lebanon NH: University Press of New England.

QuiJano, Aníbal (2000). "Coloniality of power, ethnocentrism and Latin America", Nepantla, Vol. 1, n. 3.

Rosa, Waldemir (2006). "Homem preto do gueto: Um estudo sobre a masculinidade no rap brasileiro", dissertação mestrado em antropologia, Programa de Pós-graduação em Antropologia Social, Universidade de Brasília.

SANSONE, Lívio (2004). "Negritude sem etnicidade. O local e o global nas relações raciais e na produção cultural negra do Brasil", Salvador/Rio de Janeiro, s/e.

Weller, Wivian (2010). Minha voz é tudo o que tenho. Manifestações juvenis em Berlim e São Paulo, Belo Horizonte: Editora UFMG. 